\title{
A place-based analysis of COVID-19 risk factors in Bangladesh urban slums: a secondary analysis of World Bank microdata
}

Shaikh Mehdi Hasan ${ }^{*}$ D, Susmita Das, Syed Manzoor Ahmed Hanifi, Sohana Shafique, Sabrina Rasheed and Daniel D. Reidpath

\begin{abstract}
Background: There is a lack of research investigating the confluence of risk factors in urban slums that may make them accelerators for respiratory, droplet infections like COVID-19. Our working hypothesis was that, even within slums, an inverse relationship existed between living density and access to shared or private WASH facilities.

Methods: In an exploratory, secondary analysis of World Bank, cross-sectional microdata from slums in Bangladesh we investigated the relationship between intra-household population density (crowding) and access to private or shared water sources and toilet facilities.

Results: The analysis showed that most households were single-room dwellings (80.4\%). Median crowding ranged from $0.55 \mathrm{~m}^{2}$ per person up to $67.7 \mathrm{~m}^{2}$ per person. The majority of the dwellings (83.3\%), shared both toilet facilities and the source of water, and there was a significant positive relationship between crowding and the use of shared facilities.

Conclusion: The findings highlight the practical constraints on implementing, in slums, the conventional COVID19 management approaches of social distancing, regular hand washing, and not sharing spaces. It has implications for the management of future respiratory epidemics.
\end{abstract}

Keywords: COVID-19, Urban slums, WASH, Crowding

\section{Background}

In January 2020, the COVID-19 appeared in the city of Wuhan, China marking the beginning of a global pandemic [1]. The disease is caused by the severe acute respiratory syndrome coronavirus 2 (SARSCoV2) which has person-to-person transmission qualities common to many respiratory viral infections [2].

The virus is picked up by the hands from contact with people and fomites, and transferred from the hands to

*Correspondence: smehdi@icddrb.org

International Centre for Diarrhoeal Disease Research, Bangladesh, Health

System and Population Studies Division, Mohakhali, Dhaka 1212, Bangladesh the eyes, nose or mouth [3]. In confined spaces, it may be carried in aerosolized, speech droplets [4]. The prevalent public health messages about the prevention of transmission are consistent with our understanding of droplet infections (e.g., [5]).

- Wash hands regularly with soap and water or an alcohol-based hand sanitizer;

- Avoid touching eyes, nose and mouth;

- Cover your mouth and nose with your bent elbow or tissue when you cough or sneeze and then

(c) The Author(s). 2021 Open Access This article is licensed under a Creative Commons Attribution 4.0 International License, which permits use, sharing, adaptation, distribution and reproduction in any medium or format, as long as you give appropriate credit to the original author(s) and the source, provide a link to the Creative Commons licence, and indicate if changes were made. The images or other third party material in this article are included in the article's Creative Commons licence, unless indicated otherwise in a credit line to the material. If material is not included in the article's Creative Commons licence and your intended use is not permitted by statutory regulation or exceeds the permitted use, you will need to obtain permission directly from the copyright holder. To view a copy of this licence, visit http://creativecommons.org/licenses/by/4.0/ The Creative Commons Public Domain Dedication waiver (http://creativecommons.org/publicdomain/zero/1.0/) applies to the data made available in this article, unless otherwise stated in a credit line to the data. 
dispose of the used tissue immediately and wash your hands;

- Maintain at least $1 \mathrm{~m}$ (in some advice $2 \mathrm{~m} \mathrm{[6])}$ distance between you and others;

- Avoid crowded places;

There is additional advice for those who develop symptoms of COVID-19 infection or have been in close contact with someone with COVID-19. The additional advice focuses on physical isolation $[7,8]$.

- Do not leave your home for any reason;

- Remove vulnerable people from the household, and if that is not possible "stay away from them as much as possible";

- Do not share towels;

- clean objects and surfaces you touch often;

- clean a shared bathroom each time you use it.

The combined messaging can be reduced to the need for (i) space, distance and isolation, (ii) water, sanitation and hygiene (WASH), and (iii) behavioral cough/sneeze etiquette. The third element of the message is broadly about individual behavior whereas the first two elements (space, distance and isolation, and WASH) are structural in nature. Structural elements are classically associated with a sociological literature around "structure and agency", and the social determinants of health literature $[9,10]$. An individual may intend to distance himself or herself and engage in appropriate hygiene but if the structural support is unavailable, the intention alone is insufficient.

Urban slums have been identified as potential hotspots for the spread of COVID-19, [11] and have been identified as reservoirs for the spread of other viral respiratory infections [12]. There is an obviousness to that identification: slums are crowded and poor, with a lack of access to basic utilities [13]. Notwithstanding the "self-evident" nature of the risk factors, there has been no quantification of those risk factors. Furthermore, slums are not homogenous urban spaces and the risk factors are unlikely to be distributed uniformly across the population of residents [14]. One might imagine, for instance, that those households that are more crowded are also less likely to have easy access to water for bathing and general hygiene.

The lack of empirical work in this area is unsurprising given the speed with which the pandemic has evolved. We identified only one review article of COVID-19 and slums, [15] and there were a few papers on preprint servers. None of the papers, however, utilized individual or household level data to quantify the presence of risk factors, or their co-occurrence.
In this research we examine the relationship between crowding and access to WASH facilities, with a working hypothesis that there is an inverse relationship such that more crowded living conditions are also associated with poorer access to WASH.

\section{Methods}

A secondary analysis was conducted of the publicly available microdata from the World Bank's Bangladesh "Urban Informal Settlements Survey 2016" [16, 17]. The cross-sectional, household survey was based on a sample of 600 households (588 responding households) in 63 urban slums. A single informant provided information for each household. The survey used a mixed sampling design ensuring the capture of data from small, medium and large slums. Unfortunately, the published microdata does not include sampling weights. An unweighted, model based analysis of the data is presented here.

In keeping with the strategies listed in the introduction for limiting the spread of the coronavirus, the analysis focuses on the number of people living in each dwelling, the degree of crowding, and whether toilet facilities and/ or the source of water "for bathing, cooking and other purposes" (i.e., WASH) were shared amongst dwellings.

A simple, WASH score was developed according to the availability of shared or sole-use toilet facilities and shared or sole-use of water facilities, including water for bathing and general hygiene. The best WASH availability (i.e., the lowest score) was a dwelling with sole use toilet facilities and sole use of water for bathing. A moderate WASH score was associated with the shared use of either toilet or water sources, but not both. The highest WASH score was associated with shared toilets and bathing water sources. Crowding was calculated as the number of people living in a dwelling divided by the area $\left(\mathrm{m}^{2}\right)$ of the dwelling.

The relationship between crowding and the WASH score was formally tested using a non-parametric, Kruskal-Wallis test and complemented with pairwise analyses using Wilcoxon's test with a correction for the false discovery rate associated with multiple comparisons [18]. The median and 95\% confidence intervals were reported where confidence intervals were estimated using a bias corrected and accelerated $(\mathrm{BCa})$ bootstrap with 4000 resamples [19]. It is worth noting that a BCa confidence interval around a median will be asymmetrical if the distribution (as anticipated) is skewed. All analyses were conducted in the R statistical environment [20].

\section{Results}

A total of 2516 people lived in the 588 surveyed dwellings. The median and modal number of people per dwelling was 4 and the mean was 4.3. Around $10 \%$ of residents were under 5 years of age $(n=261)$, and 5\% 
were over $60(n=126)$ - a high risk category for COVID-19 fatality.

Most dwellings comprised a single room $(n=473$, $80.4 \%), 15.1 \%(n=89)$ were two-room dwellings, and $4.4 \%(n=26)$ were dwellings of three or more rooms. The minimum dwelling size was $1.9 \mathrm{~m}^{2}$ and the maximum was (a seemingly implausible) $135.5 \mathrm{~m}^{2}$. The median dwelling size was $11.7 \mathrm{~m}^{2}$ and the mean was 14.9 $\mathrm{m}^{2}$. Crowding within dwellings ranged from $0.55 \mathrm{~m}^{2}$ per person up to $67.7 \mathrm{~m}^{2}$ per person. The median density was $2.9 \mathrm{~m}^{2}$ per person and the mean $3.8 \mathrm{~m}^{2}$ per person. The US Army Public Health Command recommends a minimum of $6.7 \mathrm{~m}^{2} /$ person in sleeping accommodation alone (i.e., barracks) [21]. Using this benchmark, 91.7\% of the slum dwellings were all over-crowded, and more than $50 \%$ of the dwellings had less than half the recommended area per person.

Figure 1 shows a plot of the level of crowding in dwellings according to the WASH score. The median crowding and the bootstrap 95\% confidence intervals are also shown. Six dwellings with, extreme values for crowding are excluded from the figure (though not the calculations of the medians or $95 \%$ confidence intervals).

There are a few observations to be made about the figure. First, the great majority of dwellings $(n=490$, 83.3\%) share both toilet facilities and the source of water for bathing, cooking and other purposes. Far fewer dwellings share either toilet or bathing facilities (but not both) $(n=69,11.7 \%)$. Just under $5 \%$ of dwellings have sole use toilet and bathing facilities $(n=29,4.9 \%)$. There, visually, appears to be a doseresponse relationship between the WASH score and crowding. The median level of crowding is greatest in dwellings that use both shared toilet and bathing facilities (median $=2.9 \mathrm{~m}^{2} /$ person, $95 \% \mathrm{CI}$ : 2.63-2.93) followed by dwellings that share only toilet or bathing facilities (median $=3.34 \mathrm{~m}^{2} /$ person, 95\%CI: 2.79-3.34) with the least crowded dwellings being those that have sole use toilet and bathing facilities (median = $5.73 \mathrm{~m}^{2} /$ person, 95\%CI: 4.18-6.5). Dwellings with the highest WASH scores reported sharing facilities with a mean of 15.8 other dwellings and 79.3 other people. Dwellings with moderate WASH scores reported sharing facilities with a mean of 13.1 other dwellings and 60.4 other people.

The difference in the distribution of crowding for each of the WASH scores was formally tested using a Kruskal-Wallis test $\quad$ (chi-squared $=33.9, \quad \mathrm{df}=2$, $p<.0001)$. Wilcoxon's test, pairwise comparisons were made between sole use and shared toilet and bathing facilities $(p<.0001)$, sole use and shared toilet or bathing facilities $(p<.0001)$, and shared toilet and bathing facilities, and shared toilet or bathing facilities $(p=.022)$.

\section{Discussion}

Slums are by their very nature informal spaces, lacking enforced building codes [22]. It is hardly surprising, therefore, to learn that Bangladesh slums are crowded spaces with poor washing and toileting facilities. It is important to note, however, that the risk factors co-varied. The more crowded the dwelling, the more likely that WASH was also shared; i.e., being at greater risk of infection from one factor is associated with being at greater risk from another factor.

There is no, single, public health recommendation about the maximum level of crowding that is acceptable to limit the spread of droplet infections. Space alone cannot be the determining factor. Ventilation will affect the degree to which aerosolized particles may be hazardous. Evidence suggest that ventilation affects the spread of diseases like measles, chicken pox, influenza, tuberculosis, small pox, SARS and SARS-CoV-2 [23]. For diseases like influenza, airborne transmission occurs in two ways. First, through relatively large respiratory fluid droplets $\left(10^{1}-10^{2} \mu \mathrm{m}\right)$ that settles on surfaces due to gravitational pull and requires close proximity for transmission. Second, finer particles $\left(\leq 10^{1} \mu \mathrm{m}\right)$ remain aerosolized and can be transmitted further away from the immediate vicinity of the infected person. For the latter source of infection, adequate ventilation is an important strategy to limit outbreaks [24]. Although the importance of the relative contribution of different modalities of infection for COVID-19 remains to be fully identified, limiting airborne transmission through improvement of ventilation, appropriate building engineering are thought to be important, along with the maintenance of regular hand washing and avoidance of shared spaces/facilities [25].. Around 627 million people worldwide share sanitation facilities [26]. As contact transmission is one of the important ways for the spread of the COVID-19 virus, infected taps, doors, knobs, toilets and handwashing surfaces can all effectively propagate the spread of the pandemic [26]. Furthermore, if there are peak times of use, as people from different households mix, the potential for aerosol transmission increases.

Prior research from slums in Bangladesh identified that nearly $82 \%$ of the slum households are single room dwellings and $48 \%$ possess a dwelling area of less than $9.3 \mathrm{~m}^{2}$ [27]. The current study suggests that more than $90 \%$ of slum dwellings are overcrowded, even according to the minimalist view of non-crowding adopted here. Moreover, the majority of the households possess WASH risk that makes them almost defenseless against COVID-19 infection. Data from the slums in Dhaka reported that toilet sharing $(90 \%)$ is a very common phenomenon in the slums. Nearly $32 \%$ of the slum households shared their latrines with 10 or more 


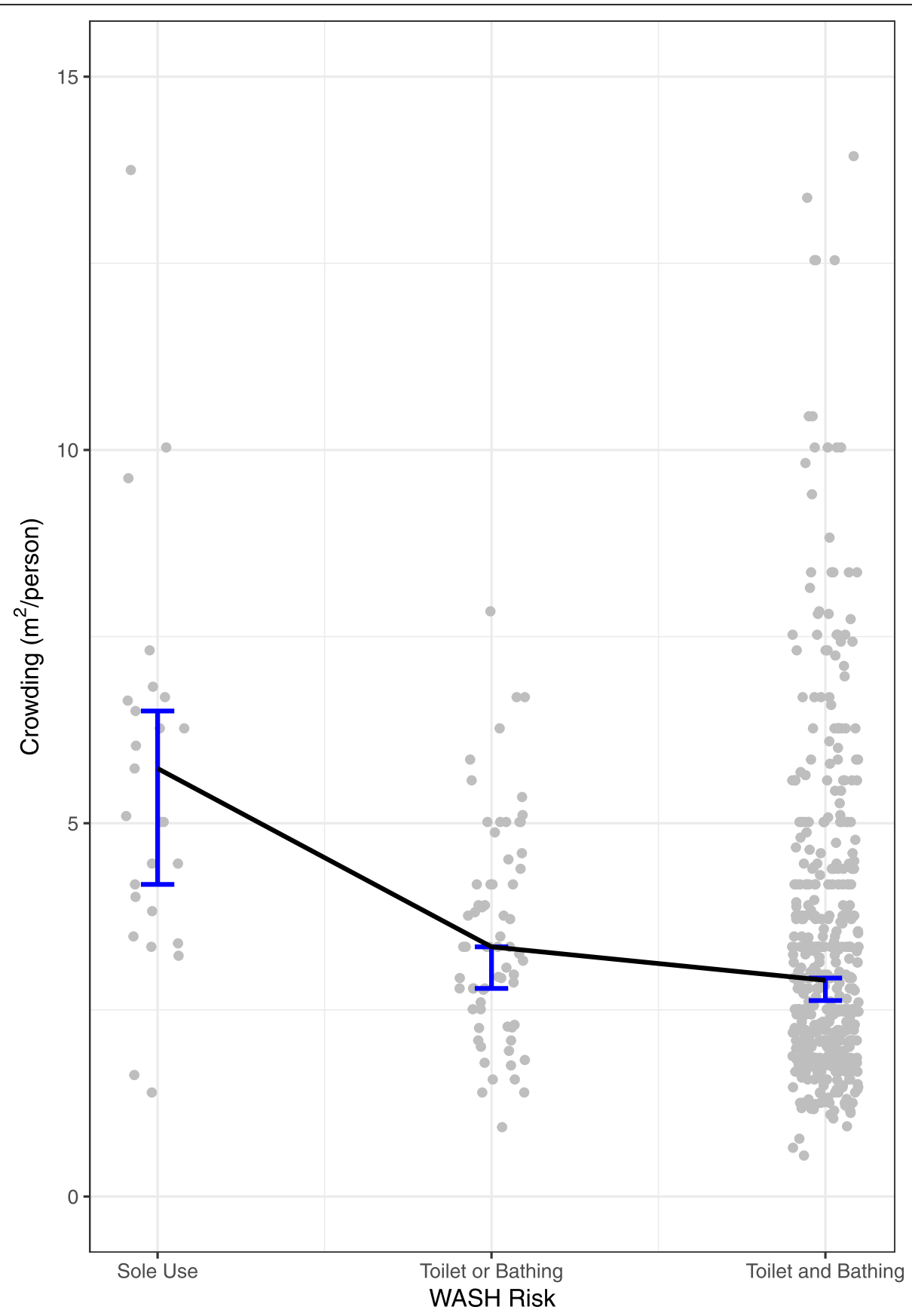

Fig. 1 a plot of the level of crowding in dwellings according to the WASH score

households, 32.4\% shared their latrines with 5-9 households and $26.2 \%$ with 1-4 households [27].. This level of vulnerability was similarly identified in previous work on social distancing in Indian slums [28]..

South Asia is home to some of the biggest slums in the world, with a substantial portion of its population living in these squalid arrangements of crowded, unhygienic conditions. COVID- 19 has the potential to spread across the slums of Mumbai (Dharavi), Karachi, Dhaka (Korail), and engulf the megacities housing them and beyond [29]. The pandemic has exposed the health security risks of the urban slums and will perhaps allow us to rethink urban development. History will show that slums were or were not implicated in the COVID-19 pandemic. This analysis, however, highlights the likely risks of slums as incubators and accelerators of infectious respiratory disease. In a recent national COVID-19 seroprevalence study, conducted by the Institute of Epidemiology Disease Control and Research (IEDCR) in collaboration with icddr,b, the seroprevalence of 
COVID-19 IgG and/or IgM was found to be $45 \%$ in Dhaka city and $74 \%$ in the slums [30].. Armed with this knowledge, it is important to consider the slum realities and rethink contextualized and novel short-term and long-term pandemic management approaches that focus on the intersections of urban planning and health service delivery improvement [31]. The contextual realities of slum are a complex mixture of numerous social, cultural and political factors that influence attitude and practice, and ultimately affect the success of any WASH related interventions [32].. In Bangladesh, most of the slums are built on government land and rented out to the dwellers, who are usually rural-urban migrants. The informal nature of residency does not allow for public utility services like water and electricity.

Politics play an important role in these settlements both internally and externally. Politically well-connected people usually control the slums and the available services. Politics, poverty, marginalization and discrimination against poor neighborhoods also influences the maintenance or destruction of such informal settlements [32]. The 'illegality' and the 'temporariness' of the settlements and the associated insecurity shapes the relevant sanitation and hygiene practices of the slum dwellers [32]. The fact that Bangladeshis are 'washers' [use water for defecation and urination] also creates more pressure on the availability on the availability of these resources in the informal settlements [32].

In many low- and middle-income countries around the world this pandemic has provided an opportunity to rethink urban development with a renewed focus on infection control in slums. Examples include the provision of portable hand washing stations in Kenya and plans in Namibia to "decongest" informal settlements through to intensive screening and testing in Dharavi slums in Mumbai, [33]. Low cost, sustainable, effective interventions or strategies need to be devised in the light of the complex socio-spatial, community and governance dynamics of slums. For example, effectiveness of cheaper, acceptable local innovations like soapy water solution against COVID-19 should be evaluated [34].

The COVID-19 pandemic is not ending soon and it will not be the last infectious disease epidemic to sweep through a megacity. It would be wise for us to learn the painful lessons that it offers.

\section{Conclusion}

Slums pose an intricately woven set of health impediments that make it challenging to mount an appropriate response to the COVID-19 pandemic. They represent a confluence of informality, overcrowding, and poor infrastructure all of which increase the risk of exposure to COVID-19 [35]. Slums are also a significant source of low cost labour for megacities and can, therefore, become accelerators and incubators of epidemics [35]. Conventional containment measures don't work within slum settings increasing their potential effect [35]. COVID-19, nonetheless, has provided an enormous, positive opportunity to rethink solutions to the entangled, 'wicked problem' of urban slums in epidemic control [36].. It has also implications for the management of future respiratory epidemics.

\section{Abbreviations \\ icddr,b: International Centre for Diarrhoeal Disease Research; SARS CoV2: Severe acute respiratory syndrome coronavirus 2; SARS: Severe acute respiratory syndrome; SIDA: Swedish International Development Cooperation Agency; UK: United Kingdom; WASH: Water sanitation and hygiene \\ Acknowledgements \\ The authors were funded by the Swedish International Development Cooperation Agency (SIDA) (SIDA Contribution No. 54100089). icddr,b acknowledges with gratitude the commitment of the Swedish International Development Cooperation Agency (SIDA), to its research efforts. Icddr,b is also grateful to the Governments of Bangladesh, Canada, Sweden and the UK for providing core/unrestricted support. The authors sincerely acknowledge World Bank for the microdata.}

\section{Authors' contributions}

SMH conceptualized the paper, interpreted the results, carried out literature review, took part in drafting and preparing the manuscript for submission. SD was involved in drafting and preparing the manuscript for submission. SMA, SS, and SR critically reviewed and revised the manuscript. DDR conceptualized the paper, carried out the literature review, acquired and analyzed the data, and interpreted the results, and took part in the preparation of the draft manuscript. All authors read and approved the final manuscript.

\section{Funding}

The authors were funded by the Swedish International Development Cooperation Agency (SIDA), (SIDA Contribution No. 54100089).

\section{Availability of data and materials}

The data used for this secondary analysis are publicly available in the World Bank Micro data library. Link: https://microdata.worldbank.org/index.php/ catalog/2864

\section{Ethics approval and consent to participate}

It is a secondary analysis of publicly available microdata. There ethical approval and consent to participate are not applicable.

\section{Consent for publication}

This is a secondary analysis of publicly available microdata from the World Bank's Bangladesh "Urban Informal Settlements Survey 2016". The data is available in the World Bank Micro data library. The authors have obtained institutional clearance from icddr,b for publication.

\section{Competing interests}

None of the authors have any competing interest.

Received: 27 September 2020 Accepted: 12 January 2021 Published online: 15 March 2021

\section{References}

1. World Health Organization. Coronavirus disease 2019 (COVID-19). Geneva: WHO; 2020. Report No.: 42. Available from: https://www.who.int/docs/ default-source/coronaviruse/20200302-sitrep-42-covid-19.pdf

2. Bennett L, Waterer G. Control measures for human respiratory viral infection. SeminRespirCrit Care Med. 2016;37:631-9.

3. Adhikari SP, Meng S, Wu Y-J, Mao Y-P, Ye R-X, Wang Q-Z, et al. Epidemiology, causes, clinical manifestation and diagnosis, prevention and control of coronavirus disease (COVID-19) during the early outbreak period: a scoping review. Infect Dis Poverty. 2020;9:29. 
4. Stadnytskyi V, Bax CE, Bax A, Anfinrud P. The airborne lifetime of small speech droplets and their potential importance in SARS-CoV-2 transmission. Proc Natl Acad Sci U S A. 2020;117(22):11875-77. https://doi.org/10.1073/ pnas.2006874117.

5. World Health Organization. Coronavirus disease (COVID-19) advice for the public. 2020. Available from: https://www.who.int/emergencies/diseases/ novel-coronavirus-2019/advice-for-public. Cited 2020 May 11

6. Public Health England. Coronavirus (COVID-19): What is social distancing? Public health matters: Public Health Matters; 2020. Available from: https:// publichealthmatters.blog.gov.uk/2020/03/04/coronavirus-covid-19-what-issocial-distancing/. Cited 2020 May 11

7. National Health Service, UK. Self-isolation if you or someone you live with has coronavirus symptoms - Coronavirus (COVID-19): nhs.uk; 2020 Available from: https://www.nhs.uk/conditions/coronavirus-covid-19/ what-to-do-if-you-or-someone-you-live-with-has-coronavirus-symptoms/ staying-at-home-if-you-or-someone-you-live-with-has-coronavirussymptoms/. Cited 2020 May 11

8. Public Health England. Stay at home: guidance for households with possible coronavirus (COVID-19) infection: GOV.UK; 2020. Available from: https://www.gov.uk/government/publications/covid-19-stay-at-homeguidance/stay-at-home-guidance-for-households-with-possible-coronaviruscovid-19-infection. Cited 2020 May 11

9. Williams $\mathrm{GH}$. The determinants of health: structure, context and agency. Sociol Health IIIn. 2003;25:131-54.

10. Short SE, Mollborn S. Social determinants and health behaviors: conceptual frames and empirical advances. Curr Opin Psychol. 2015;5:78-84.

11. Sharif MM. Opinion: Slums are the next front line in the fight against the coronavirus. Devex News. 2020; Available from: https://www.devex.com/ news/sponsored/opinion-slums-are-the-next-front-line-in-the-fight-againstthe-coronavirus-97088. Cited 2020 May 12

12. Adiga A, Chu S, Eubank S, Kuhlman CJ, Lewis B, Marathe A, et al. Disparities in spread and control of influenza in slums of Delhi: findings from an agent-based modelling study. BMJ Open. 2018;8:e017353.

13. Davis M. Planet of slums. London: Verso; 2017.

14. Das DN, Bhusan S. Living in blight in the globalized metro: a study on housing and housing conditions in slums of Delhi. In: Acharya SS, Sen S, Punia M, Reddy S, editors. Marginalization glob Delhi issues land livelihoods health. New Delhi: Springer India; 2017. p. 431-65. Available from: https:// doi.org/10.1007/978-81-322-3583-5_24. Cited 2020 May 13.

15. Corburn J, Vlahov D, Mberu B, Riley L, Caiaffa WT, Rashid SF, Ko A Patel S, Jukur S, Martínez-Herrera E, Jayasinghe S, Agarwal S, NguendoYongsi B, Weru J, Ouma S, Edmundo K, Oni T, Ayad H. Slum Health: Arresting COVID-19 and Improving Well-Being in Urban Informal Settlements. J Urban Health. 2020;97(3):348-57. https://doi.org/10.1007/ s11524-020-00438-6.

16. Yanez-Pagans M. Urban Informal Settlements Survey 2016: World Bank; 2016. Available from: https://microdata.worldbank.org/index. HYPERLINK "https://microdata.worldbank.org/index.php/catalog/2864"php/catalog/2864. Accessed 9 Apr 2020.

17. Arias-Granada Y, Haque SS, Joseph G, Yanez-Pagans M. Water and Sanitation in Dhaka Slums: Access, Quality, and Informality in Service Provision. Washington, DC: The World Bank; 2018. Report No.: 8552. Available from: https://elibrary.worldbank.org/doi/abs/10.1596/1813-9450-8552

18. Benjamini Y, Hochberg Y. Controlling the False Discovery Rate: A Practical and Powerful Approach to Multiple Testing. J R Stat SocSer B Methodol [Royal Statistical Society, Wiley]. 1995;57:289-300.

19. Efron B, Tibshirani RJ. An introduction to the bootstrap. 1st ed. Boca Raton: Chapman \& Hall/CRC; 1994.

20. R Core Team. R: a language and environment for statistical computing Vienna: R Foundation for Statistical Computing; 2019. Available from: https://www.R-project.org/

21. United States Army. Facility Sanitation Controls and Inspection. Washington DC: United States Army; 2019. Report No.: TB MED 53

22. UN-Habitat. Informal Settlements. New York: United Nations Human Settlements Programme; 2015. Report No.: 22

23. Li Y, Leung $G$, Tang J, Yang $X$, Chao $C$, Lin J, et al. Role of ventilation in airborne transmission of infectious agents in the built environment - a multidisciplinary systematic review. Indoor Air. 2007;17:2-18.

24. Smieszek T, Lazzari G, Salathé M. Assessing the Dynamics and Control of Droplet- and Aerosol-Transmitted Influenza Using an Indoor Positioning System. Sci Rep. 2019;9:2185 Nature Publishing Group.
25. Morawska L, Tang JW, Bahnfleth W, Bluyssen PM, Boerstra A, Buonanno G, et al. How can airborne transmission of COVID-19 indoors be minimised? Environ Int. 2020;105832.

26. Kotwal, Nandita, Gilsdorf, Rebecca J., Mehta Nishtha, Gambrill Martin. To share or not to share sanitation facilities: a coronavirus conundrum. July 30, 2020. World Bank Blogs.

27. Islam M, Adams A, Mahmood S, lqbal M, Chowdhury R, Razzaque A, et al. Slum Health in Bangladesh: Insights from Health and Demographic Surveillance. Dhaka: International Centre for Diarrhoeal Disease Research, Bangladesh (icddr,b); 2019.

28. Wasdani KP, Prasad A. The impossibility of social distancing among the urban poor: the case of an Indian slum in the times of COVID-19. Local Environ Routledge. 2020;25:414-8.

29. ESCAP (Economic and Social Commission for Asia and the Pacific) United Nations. COVID-19 and South Asia: National Strategies and Subregional Cooperation for Accelerating Inclusive, Sustainable and Resilient Recovery. 2020. https://www.unescap.org/resources/covid-19-and-south-asia-nationalstrategies-and-subregional-cooperation-accelerating. Accessed 25 July 2020.

30. Press release. The IEDCR and partners share insights on the prevalence, seroprevalence and genomic epidemiology of COVID-19 in Dhaka city. https://www.icddrb.org/quick-links/press-releases?id=97\&task=view. Accessed 15 Oct 2020

31. World Bank Group. COVID-19 and the Urban Poor Addressing those in slums. http://pubdocs.worldbank.org/en/304801589388481883/AddressingCOVID-19-and-the-Urban-Poor-SHORT-version-rev3-logos.pdf. Accessed 25 July 2020.

32. Rahman M, Mizanur A, Peter J, McFarlane C. Factors affecting slum sanitation projects in Dhaka City: learning from the dynamics of socialtechnological -governance systems. J Water Sanit Hyg Dev. 2014;4(3):34658.

33. World Bank Group. Global Responses to COVID-19 in slums and cities. Practices from around the world. 2020.

34. Amin N, Pickering AJ, Ram PK, Unicomb L, Najnin N, Homaira N, Ashraf S, Abedin J, Islam MS, Luby SP. Microbiological Evaluation of Efficacy of Soapy Water to Clean Hands: A Randomized, Non-Inferiority Field Trial. Am J Trop Med Hyg. 2014;91(2):415-23.

35. World Bank Group. COVID-19 and slums: WBG LAC: A multisectoral approach. Published on June 30, 2020. https://www.thegpsc.org/ knowledge-products/urban-poverty-and-housing. Accessed 25 July 2020.

36. Mukherjee J., Sen A. From SMART to sustainable cities: Is COVID19 an opportunity? 2020. https://www.o HYPERLINK. https://www.orfonline.org/ expert-speak/from-smart-to-sustainable-cities-is-covid19-anopportunity-66363/. Accessed 25 Oct 2020.

\section{Publisher's Note}

Springer Nature remains neutral with regard to jurisdictional claims in published maps and institutional affiliations.

Ready to submit your research? Choose BMC and benefit from:

- fast, convenient online submission

- thorough peer review by experienced researchers in your field

- rapid publication on acceptance

- support for research data, including large and complex data types

- gold Open Access which fosters wider collaboration and increased citations

- maximum visibility for your research: over $100 \mathrm{M}$ website views per year

At $\mathrm{BMC}$, research is always in progress.

Learn more biomedcentral.com/submission 